\title{
A regulatory perspective on the potential carcinogenicity of glyphosate
}

Yehia A. Ibrahim

Correspondence: prof.dr.yehia.ibrahim@gmail.com

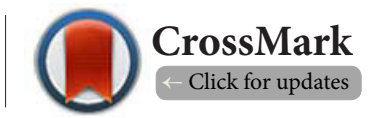

Professor of Pesticide Chemistry and Toxicology, Assiut University and Deputy Chairman of the Agricultural Pesticide Committee (APC), Ministry of Agriculture and Land Reclamation, Arab Republic of Egypt.

\begin{abstract}
Background: On March 20th of 2015, the International Research on Cancer (IARC), affiliated with the World Health Organization (WHO), classified two organophosphate insecticides (malathion and diazinon) and one herbicide (glyphosate) as "probably carcinogenic to humans" (Group 2A). Because these pesticides are currently registered in Egypt, the Senior Management Team (SMT) of the Agricultural Pesticide Committee (APC), Ministry of Agriculture and Land Reclamation, was held on the following day of the IARC designation, and assigned the author of this review to make a case study particularly on glyphosate due to its uniqueness and the recent controversial views regarding its human and environmental safety. Even though the IARC classification has no mandatory impact on regulatory agencies, it was decided to conduct a review of the toxicological evidence on glyphosate and its current regulatory status in the International Pesticide Regulatory Agencies/Authorities. This review-based report is intended to help pesticide regulatory agencies in the third world countries through case-modeling.
\end{abstract}

Methods: Given the very serious implications of the recent and controversial IARC designation of glyphosate as 'probably carcinogenic to humans (Group 2A), the author of this report has invested substantial effort in reviewing voluminous scientific and regulatory publications. In order to reach an appropriate level of objectivity and fairness, the author will shed some lights on critical research/ review articles that cover two extremist views regarding the human safety of glyphosate, i.e., one that ultimately questions glyphosate safety and the other that ultimately considers glyphosate safe and poses no carcinogenic, genotoxic or reproductive risks to humans.

$\underline{\text { Results: }}$ This review has clearly indicated that IARC designation of glyphosate is in contradiction with an overwhelming consensus among the World's most robust and stringent pesticide regulatory agencies/ authorities as well as many reputable international scientific and research organizations. In particular, all the agencies/authorities that are currently regarded by APC as reference organizations in the committee's registration or re-registration eligibility decisions of agricultural pesticides continually viewed glyphosate as a safe pesticide with no evidence of human carcinogenicity. Furthermore, three other WHO-affiliated programs agree on glyphosate safety-namely the WHO Core Assessment Group, the WHO Guidelines for Drinking-Water Safety and the WHO International Programme on Chemical Safety.

Conclusion: It appears that IARC has overreached in its conclusion by failing to consider the vast body of literature supporting the notion that glyphosate is not a carcinogen. Besides, IARC has failed to place potential hazard into a context of actual risk. When the conditions of glyphosate use in Egypt is rationally analyzed, it appears that exposure of the public to glyphosate is order of magnitudes far below the zero-risk dose. Therefore, glyphosate can be continually used in Egypt with some restriction measures to minimize its risk even further.

Keywords: N-(phosphonomethyl) glycine, glyphosate, carcinogenicity, genetically modified glyphosateresistant crops, pesticide risk assessment, potential hazard, exposure, actual risk 
Yehia A. Ibrahim, Journal of Toxicology and Health 2015,

\section{Background}

In the late 1960's and early 1970's, the now widely used broad spectrum herbicide, glyphosate, was synthesized and introduced for agricultural and home use [1]. Since its introduction as the primary active ingredient in Roundup ${ }^{\mathbb{R}}$ branded herbicide and after becoming generic, glyphosatebased formulations have become the most world-widely used weed killers and plant desiccators that accelerate ripening and facilitate harvesting of crops. Glyphosate formulations are sprayed on farms, in forests, on road sides, in gardens, and even in the control of cocaine production in South America. For many structural, biochemical, toxicological and practical reasons, glyphosate has a reputation for being toxicologically benign [2].

Glyphosate inhibits the specific enzyme, 5-enolpyruvylshikimate-3-phosphate synthase (EPSPS), thereby preventing plants from biosynthesizing three aromatic amino acids (tyrosine, phenylalanine and tryptophan) that are critically essential for plant growth $[3,4]$. Because its site of action is common in all plants, this herbicide is mostly non-selective between different plant species. To the contrary, humans and animals do not use EPSPS and this contributes to glyphosate not presenting unreasonable mammalian 'acute toxicity' concerns when used at the application rates required to kill weeds or unwanted plants. With respect to mammalian 'chronic and sub-chronic toxicity' and 'environmental toxicity' glyphosate has undergone extensive toxicology testing over the last forty years. Although most of the published work demonstrates the absence of concerns for developmental and reproductive toxicity, carcinogenicity, genotoxicity, endocrine disruption potential, neurotoxicity and immunotoxicity, the chronic toxicity data are not as consistent as the acute toxicity data. Published literature and the internet are full of allegations against glyphosate. Yet, supranational pesticide regulatory agencies/authorities (e.g., US-EPA, BfR, EFSA, EU, PMRA, and APVMA) have consistently dismissed these allegations and continue to approve registration of more than 2000 glyphosate-based formulations. The use of glyphosate has soared in the last two decades because of Monsanto's introduction of Roundup Ready crops that are genetically engineered to withstand glyphosate, allowing farmers to spray their fields and kill susceptible populations of weeds without harming crops.

Thirty years ago, EPA determined that the popular Roundup ${ }^{\circledR}$ might cause cancer [5], but six years later in 1991 the agency reversed itself after re-evaluating the mouse study that had been the basis for the original conclusion [6]. Now the issue is back again, in an even bigger and more serious way. On March 20, 2015, the International Agency for Research on Cancer (IARC) classified glyphosate as group 2A, e.g., "probably" causes cancer in humans $[7,8]$. One piece of evidence the agency cited was the same above-mentioned mouse study.

Although not specifically related to the IARC working group(s), it is unfortunate that from within scientific inconsist- ency, interpreters can knowingly and/or unknowingly pick up the data that support their cases. Besides, the new controversy and the reversal by EPA fourteen years ago demonstrate how the same data can be interpreted differently and how complicated and politically perilous the IARC decision can be, especially for developing countries that do not have their own risk assessment systems to rationally support their pesticide registration eligibility decisions and regulatory policies. It is commonly known that IARC looks at a very narrow question: whether a substance or behavior might cause cancer under some circumstances, even if those circumstances are unlikely to occur. Unlike pesticide regulatory agencies/authorities, IARC does not weigh the benefits versus the risks of a chemical within the framework of human exposure, leaving that up to regulators. Besides, the belief that a pesticide can be categorized as 'absolutely' carcinogenic or non carcinogenic is contrary to the basic principles of toxicology, namely, evidence for carcinogenicity can be obtained experimentally for any chemical given to the right cell line/culture or the right animal species at the right time/physiological sate, at the right dose for the right duration. This does not mean that IARC's process of conducting hazard identification for putative carcinogens is of no value. It is what it is, one step in the process. Therefore, this review-based report is meant to simply understand the controversy of glyphosate safety and to use this understanding to justify any regulatory decision regarding the future use of glyphosate in Egypt as a model example of many other developing countries. From this toxicological paradigm and based on the evaluation of glyphosate use in Egypt, which is expected to be highly similar to many other developing countries, it is suggested that the registration of this herbicide be continued within some risk-mitigation and restriction measures.

\section{Review}

This review-based report will mainly focus on the two opposite positions regarding glyphosate safety. The two positions will be analyzed not only from the hazard potential perspective, but also from the practical risk perspective. Then a list of recommendations is synthesized to possibly mitigate any risk the use of this herbicide may cause to applicators, bystanders, consumers, etc. First, let's shed some light on the structure and mode of action of this herbicide.

\section{What is glyphosate?}

Glyphosate is the active ingredient in many formulations that have been commercially used since the introduction of this chemical as herbicide in 1974. It has the chemical structure of $\mathrm{N}$-(phosphonomethyl) glycine or 2-[(phosphonomethyl) amino] acetic acid, and was first commercialized by Monsanto under the trade name Roundup ${ }^{\circledR}$ [1]. When Monsanto's patent on the use of glyphosate in herbicide formulations expired in 2000, other companies were free to develop and sell herbicides using glyphosate as the active ingredient 
under their own brand names. Since then glyphosate has been manufactured and formulated by hundreds of pesticide companies in thousands of formulations, and its cost declined significantly; thereby contributing to its dominance among other herbicides. Glyphosate is a non-selective herbicide registered for post-emergence control of a wide spectrum of weeds including annual and perennial broadleaf and grassy weeds, weedy trees and bushes. It is registered under various forms including glyphosate acid, glyphosate isopropylamine or ethanolamine salt, glyphosate mono-ammonium or diammonium salt, glyphosate potassium or sodium salt, glyphosate dimethylamine salt and glyphosate trimethylsulfonium salt. Glyphosate products are formulated as solutions, pastes or tablets and can be applied using ground or aerial equipment. Some special application techniques are also used.

\section{How does glyphosate work?}

Glyphosate is the only known herbicide that acts by interrupting the EPSPS enzyme in the shikimate pathway, a biochemical process that plants, some bacteria and fungi use to produce certain aromatic amino acids they need to survive $[3,4]$. Because it inhibits EPSPS from all higher plants, glyphosate is a non-selective herbicide, with herbicidal activity toward a very wide range of plant species including economic crops and their accompanying weeds. Unique chemical structure, unique site of action, good uptake, excellent translocation to growing sites, slow mode of action, slow evolutionary pace of weed-resistance development, low level of weed-resistance, etc. make glyphosate an ideal herbicide [9].

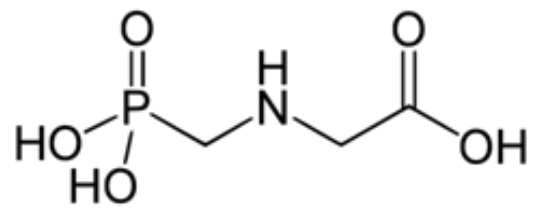

The Chemical Structure of Glyphosate

Glyphosate-based herbicide products contain additional chemicals; surfactants, to allow the active ingredient to be more easily absorbed into plant leaves. Once inside the leaves, the chemical moves into growing plant parts, where it kills tissues and prevents re-growth. The plant turns yellow and dies within two weeks or less after being sprayed. Glyphosate herbicides also contain or are mixed with adjuvants - other chemicals that enhance the performance of the active ingredient or affect other aspects such as droplet size, mixing, foaming, etc. Neither surfactants nor adjuvants are subjected to thorough acute, chronic and environmental toxicity studies. This is because pesticide regulatory agencies/authorities require such studies on the pesticide's active ingredient rather than on its whole formulation or the individual constituents of this formulation.

Until very recently human health and environmental safety of glyphosate has not been vigorously questioned and/or strongly disputed. Because it has a long reputation of being one of the least toxic pesticides to animals $[1,10,11]$ it is widely used for weed control throughout the world on industrial and agricultural lands, both in urban or recreational areas. An extremely high $\mathrm{LD}_{50}$ value for rats (greater than $5 \mathrm{~g} / \mathrm{kg}$ ) makes glyphosate appear to be less acutely toxic than some common chemicals such as sodium chloride or aspirin [1]. The notion of such exceptional safety has been used, sometimes abused, in marketing advertisement and trade promotion. Some cations, adjuvants and surfactants used with/in glyphosate-based formulations are, however, more toxic than glyphosate acid or its free anion, which may ultimately complicate the overall picture of glyphosate safety from a practical point of view as will be discussed later in this manuscript. In a lengthy and comprehensive review [2], Williams et al. concluded that glyphosate was not a carcinogen or a reproductive toxicant nor does it have any subacute chronic toxicity. When used responsibly according to label instructions, it is generally assumed that there should be no human health safety issues. Despite the publishing of some reports that questioned glyphosate human and environmental safety, the abovementioned review has been recently and strongly supported by many other articles (see the section on Critical Research and Review Articles on Glyphosate).

\section{Landmarked regulatory reports on glyphosate}

Before March 20, 2015, all regulatory authorities and independent experts around the world have reviewed numerous long-term carcinogenicity and genotoxicity studies on glyphosate. Based on their evaluation of the weight-of-evidence of glyphosate's carcinogenic potential, they generally agreed that glyphosate, as the active ingredient in Roundup ${ }^{\circledR}$ brand herbicide and other glyphosate-based formulations, is not likely to be carcinogenic or genotoxic to humans, even at very high doses.

An IARC selected working Group (17 experts from 11 countries) met on 3-10 March 2015 in Lyon, France and reviewed reports that have been published or accepted for publication in the openly available scientific literature or in governmental and regulatory reports to determine the weight-of-evidence of the carcinogenic potential of four insecticides (malathion, diazinon, tetrachlorvinphos and parathion) and one herbicide (glyphosate). On March 20, 2015, IARC announced malathion, diazinon and glyphosate as 'probably' carcinogenic to humans (Group 2A) and tetrachlorvinphos and parathion as 'possibly' carcinogenic to humans (Group 2B) [7]. This classification was officially published in a short report in the "Lancet Oncology", a medical journal [8]. The three pesticides that have been classified as probably carcinogenic to humans (Group 2A) are currently registered in Egypt. Because glyphosate is the most important herbicide both in Egypt and world-wide, it will be the main focus of this article.

Three things are worth-noting here. First, glyphosate was classified as Group 2A based on 'limited evidence' in humans 
and 'sufficient evidence' in experimental animals. Second, IARC does not consider 'risk' or likelihood of harm to humans; it only considers the strength of evidence for any intrinsic or potential 'hazard' that will not cause cancer unless human exposure exceeds certain limit or threshold. Third, the terms probably carcinogenic and possibly carcinogenic are only 'qualitative' measures of different strengths of evidence of human carcinogenicity, with 'probably' carcinogenic signifying stronger evidence than 'possibly' carcinogenic. Now let's look carefully at the critical reviews of glyphosate safety in other key pesticide regulatory agencies/authorities. For each agency/authority, these reviews will be reported in a more or less chronological pattern.

\section{The World Health Organization (WHO) and the Food and Agriculture Organization (FAO)}

In 1986, WHO and FAO of the United Nations stated in their report on pesticide residues in food that except for mild hepatotoxicity at high doses in mice, glyphosate is acutely and chronically non toxic with no evidence of either carcinogenicity or in vitro and in vivo mutagenicity [12]. The above statement was later confirmed by the WHO in its 1994 review [13]. A decade later (in 2004), WHO and FAO, in their report on pesticide residues in food, stated that long-term studies of glyphosate toxicity in mice showed no toxic effects and no evidence of carcinogenicity and genotoxicity at up to the highest dose tested (1000 mg/kg bw per day) [14]. In its pesticide specifications issue of November 2014 [15], FAO appeared to maintain the same position regarding glyphosate safety and clearly indicated that when glyphosate, as an active ingredient, was examined for mutagenicity in a wide range of test systems covering all relevant end points in vitro as well as in vivo, it does not exhibit a mutagenic risk to humans. FAO added that although glyphosate products have been in world-wide use for many decades, no solid evidence of carcinogenic effects in humans has been concomitantly reported.

\section{The European Commission (EC)}

The Health and Consumer Protection Directorate-General of the $\mathrm{EC}$ made a regulatory review on glyphosate and concluded that there was no evidence of carcinogenicity or genotoxicity that may or should prevent glyphosate re-registration for use in Europe [16]. The EC review, like many others around the world, concluded that there was no evidence that glyphosate may pose carcinogenic or genotoxic risk to humans.

\section{The US Environmental Protection Agency (US-EPA)}

The US-EPA reviewed the potential carcinogenicity of glyphosate at least three times in $1985,1986,1991[5,6]$. During these three reviews, glyphosate received three different/distinct scores of carcinogenic potential which indicates a change in the weight-of-evidence each time based on the available data and their interpretation. Surprisingly, glyphosate went from Group C (possible carcinogen to humans) in 1985 to
Group D (not classifiable as to human carcinogenicity) in 1986 to Group $\mathrm{E}$ (evidence of non-carcinogenicity for humans) in 1991. Since 1991, the US-EPA has been keeping glyphosate in Group E which is the lowest group in EPA cancer classification. The agency maintains its position and considers this herbicide as safe to human health and the environment, and does not poses any carcinogenic risk to humans when used according to label instructions.

Through personal communication between the author of this review and officials in the EPA after the IARC classification on March 20, 2015, the agency replied as follows: "In 2014, EPA reviewed over 55 epidemiological studies conducted on possible cancer and non-cancer effects of glyphosate. Our review concluded that this body of research does not show that glyphosate causes cancer, and it does not warrant any change in EPA's cancer classification of glyphosate" [17].

\section{The Canadian Pest Management Regulatory Agency (PMRA)}

Health and Welfare Canada reviewed the glyphosate toxicology database, and concluded that the acute toxicity of glyphosate is very low and the submitted studies contained no evidence that glyphosate causes mutations, birth defects or cancer [18]. Very recently (on April 13, 2015), and after a re-evaluation of available scientific information, PMRA confirmed its previous evaluation outcome indicating that glyphosate products do not present unacceptable risks to human health or the environment when used according to the proposed label instructions [19]. Accordingly, PMRA is now proposing continued registration of products containing glyphosate for sale and use in Canada. As a condition of the continued registration, new risk reduction measures are proposed for glyphosate end-use products. No additional data are being requested at this time and once the final re-evaluation decision is made, the registrant will be instructed on how to address any new requirements. Proposed Re-evaluation Decision PRVD201501-Glyphosate is a consultation document that summarizes the evaluation of the toxicological data for glyphosate and presents the reasons for the proposed re-evaluation decision. It also proposes new risk reduction measures to further protect human health and the environment. The information in Proposed Re-evaluation Decision PRVD2015-01-Glyphosate is presented in two parts: the Overview describes the regulatory process and key points of the evaluation, while the Science Evaluation provides detailed technical information on the assessment of glyphosate.

\section{Comisión Nacional de Investigación Sobre Agroquímicos Decreto 21/2009}

Argentine Interdisciplinary Scientific Council reviewed many epidemiological studies and showed no correlation between exposure to glyphosate and cancer incidence, adverse effects on reproduction, or Hyperactive-Attention-Deficit-Disorder in children [20]. Besides, it was estimated that no significant 
risks would exist for human health regarding the adverse effects on the genetic material. The council stated that under responsible use conditions of glyphosate, the intake of food and water would not imply risks for human health. This regulatory agency was added to this report because there have been public concerns and complains that glyphosate causes multiple chronic diseases in Argentine. Besides, Argentine is considered to be among few countries that use glyphosate at a much higher rate than the average use around the world. This could be due to the wide spread of crops that are genetically-engineered to withstand the herbicidal action of glyphosate at very high application rates.

\section{The Australian Pesticides and Veterinary Medicines Authority (APVMA)}

In 2013 APVMA reviewed glyphosate with respect to its safety to human health and the environment. The weight and strength of evidence shows that glyphosate is not genotoxic, carcinogenic or neurotoxic [21]. This Australian authority concluded that the weight-of-evidence gave no significant reason(s) to suggest that glyphosate products registered in Australia and used according to label instructions present any unacceptable risk to humans and the environment. APVMA has not changed its position regarding glyphosate safety even after the IARC designation of glyphosate as probably carcinogenic to humans. In 2015 APVMA claimed that the IARC assessment was only based on intrinsic 'hazard' rather than actual risk [22]. Since the intrinsic hazard is only one component of the actual risk and the exposure component was not taken into account in the IARC assessment, this assessment cannot be directly and/or fairly compared to regulatory assessments for the purpose of practical, yet well-informed, registration or re-registration eligibility decisions and related use policies wherein appropriate risk mitigation measures to allow human and environmental safety are commonly included. Accordingly APVMA maintains its position regarding glyphosate safety and continues the registration of about 200 glyphosate-containing products for use in Australia.

\section{The German Federal Institute for Risk Assessment (BfR)} Germany is the Rapporteur Member State (RMS) responsible for the ongoing re-evaluation process of glyphosate in the EU. As per this responsibility, an extensive 'Renewal Assessment Report' (RAR) was provided in 2013 and has been revised in 2014 and again in 2015 [23]. The toxicological and residue chapters of the report have been prepared by BfR. The 2013 report was circulated by EFSA to the EU Member States and was made available for public consultation in 2014. Revisions were made to take into account the several hundred comments and remarks. For the purpose of risk assessment of glyphosate, BfR has compiled the most comprehensive toxicological database, presumably world-wide. This database comprises hundreds of studies that were performed by or on behalf of the many glyphosate manufacturers and thousands of references from the scientific open literature. Evaluation of this huge amount of data and other evaluations made by supranational regulatory authorities or agencies have encouraged Prof Dr Andreas Hensel, the President of BfR, to state clearly and strongly in his Press Release of March 2014 [24] that glyphosate has no carcinogenic or embryo-damaging properties or toxicity to reproduction in test animals. These credible evaluations have also made the IARC designation of glyphosate as probably carcinogenic to humans a big surprise to the BfR. In its Communication No 007/2015, 23 March 2015 [23], BfR has strongly disputed the IARC classification and considered it as based on limited laboratory and epidemiological studies.

BfR updated its comprehensive assessment $[25,26]$, and found no evidence of carcinogenicity and there were no effects on fertility, reproduction and development of neurotoxicity that might be attributed to glyphosate. A revised health risk assessment report on glyphosate that was prepared by the BfR was discussed at the expert meeting of the European Food Safety Authority (EFSA). Subsequently, the report was again amended by the BfR. The BfR latest revision comprised additional evaluation tables as well as additional amendments for more clarification on some factual matters. On the first April, 2015 BfR sent this supplemented and revised version of the report to the Federal Office of Consumer Protection and Food Safety (BVL) for forwarding to the EFSA. Thus BfR's contribution in the context of the EU-approval process was finalized. The BfR recommends emphatically that all those involved in the assessment of glyphosate, WHO panels, IARC and JMPR (Joint FAO/WHO Meeting on Pesticide Residues), as well as the competent EU-authorities, EFSA and ECHA, should discuss the current disputable issues, with the aim of resolving the discrepancies, before the EU-Commission makes a decision on the further approval of glyphosate. Because it considers its review as more comprehensive and based on a larger size of high quality research database, BfR sustains its position regarding glyphosate as being unlikely to pose a carcinogenic risk in humans even after the IARC conclusion on March 20, 2015.

After the announcement of IARC on glyphosate, the author of this study contacted the International Pesticide Regulatory Agencies/Authorities that have been assigned by the Ministerial Decree of Agricultural Pesticide Regulation in Egypt (Directive 1018/2013) to be the reference organizations upon which APC relies in initiating the decision-making process of pesticide registration or re-registration eligibility. EPA, PMRA, APVMA and EFSA/EU responded in a way as if they all maintain their position on solid grounds and consider glyphosate as being safe and pose no carcinogenic risks to humans.

\section{Critical research and review articles on glyphosate}

In order to reach an appropriate level of objectivity and fairness, this review-based report will shed some light on critical research/review articles that cover two extremist views 
Yehia A. Ibrahim, Journal of Toxicology and Health 2015,

regarding the human safety of glyphosate. This section will start with articles that utmost question glyphosate safety and end up with those that consider glyphosate safe and poses no carcinogenic, genotoxic or reproductive risks to humans. Special emphasis will be given to the most recent research and review articles.

Despite the fact that there are some published reports indicating the potentiality of glyphosate to induce cancer in the USA [27]; human chronic kidney disease (CKDu) in Sri Lanka [28] and mammary tumors and endocrine disruption in rats [29], many from the scientific community disputed these findings fiercely. The First study was based on correlation between many chronic diseases and the use of glyphosate or GM crops that are resistant to glyphosate. Using the criteria of causative evidence, it seems that this study lacks solid evidence for cause-effect relationships between glyphosate exposure and increase in cancer incidence. In a personal communication with Dr. Nancy Swanson disputing her conclusion about glyphosate's exposure/cancer causal relationship, her reply added no reason(s) to fully refute the apparent but likely coincidence relationship [30]. Dr. Channa Jayasumana from Sri Lanka hypothesized that glyphosate acts as a carrier to nephrotoxic metals, therefore, indirectly causes chronic kidney disease [28]. In a personal communication with him he indicated that there is not enough data to conclude any carcinogenic risk of glyphosate [31]. Since the third study [29] created what is called: 'The Séralini Affair', it will be reported below in much further details.

On September 19, 2012 Séralini and his research team published a metamorphic earth-quacking study in the journal of Food and Chemical Toxicology [29]. This study was about a long term (2-year) toxicity of glyphosate and genetically-engineered glyphosate-resistant maize in rats. Treated animals showed many signs of severe chronic toxicity that include: early death, large palpable tumors, organ and gland disability, hormonal imbalance, liver congestions and necrosis, marked and severe kidney nephropathies and significant chronic kidney deficiencies. These effects were hormone- and sex-dependent, and the pathological profiles were comparable. The authors explained their results as due to non-linear endocrine-disrupting effects of glyphosate, as well as an over-expression of glyphosate-resistance gene(s) in transgenic maize.

Once the paper was published, various types of stormy and fierce criticism from individual scientists, regulatory agencies and pesticide companies disputing the validity of Séralini's work have erupted. Critiques questioned the validity of the authors' conclusions because they were based on flawed experimental design, few numbers of experimental animals in each treatment or study group, and improper strain of the experimental animal species (Sprague-Dawley rat). Some critiques have even gone further to another dimension, e.g., allegation(s) of fraud and/or intentional misinterpretation(s). Due to the nature of the concern raised, the Editor-in-Chief of the journal of Food and Chemical Toxicology examined all aspects of the review process as well as the raw data that were obtained upon request from the senior author of the published article [29]. On November 28, 2013 Elsevier [32] announced that the article has been retracted by and from the journal because of technically objective rather than vaguely subjective reasons.

In trying hard to keep some qualitative balance in this review-based report and after reviewing three of the most glyphosate-damaging articles, we will quickly run through some very recent reviews or research articles that stand firmly at the extreme and opposite end of the human safety yardstick and emphasize that glyphosate poses no risk to humans.

In 2000, an international panel of toxicologists published a peer-reviewed assessment of voluminous studies on glyphosate [2]. They concluded that multiple lifetime animal feeding in standard assays conducted according to international guidelines have failed to demonstrate any carcinogenic or genotoxic potential of glyphosate. On the basis of this assessment, glyphosate appeared to pose no risk of producing heritable or somatic mutations.

In 2012 a group of epidemiologists reviewed seven cohort studies and fourteen case-control studies to examine any possible association between glyphosate exposure and one or more cancer outcomes [33]. The authors of this review failed to observe any consistent pattern(s) of causal relationship between exposure to glyphosate and total cancer in adults or children on one hand, or between exposure to glyphosate and site-specific cancer on the other hand.

In 2013, two scientists reviewed many genotoxicity publications and regulatory studies of glyphosate and glyphosatebased formulations (GBFs). When all the findings were incorporated into a weight-of-evidence for genotoxic potential, the reviewers found an overwhelming prevalence of negative results in well-conducted assays including bacterial reversion, in vivo mammalian micronucleus, and chromosomal aberration. They concluded that glyphosate and GBFs are not genotoxic in these core assays [34]. In 2015, the earlier conclusion was confirmed by data derived from experimental genotoxicity studies [35]. Collectively, these two publications $[34,35]$ indicate clearly that typical GBFs do not present any significant genotoxic risk under normal conditions of human or environmental exposure.

In 2015 a review was published on fourteen cancer studies conducted over the last several decades in rats and mice [36]. The general conclusion that came out of this review is that no solid evidence could be synthesized from these studies to indicate that glyphosate causes cancer. The reviewers also evaluated the data from these long-term studies to determine any pattern(s) suggesting that exposure to glyphosate would have any concern about developing human cancer. Other relevant information such as human dietary exposures, epidemiological studies and regulatory evaluations were also reviewed. In brief, a consistent view based on relevant 
Yehia A. Ibrahim, Journal of Toxicology and Health 2015,

information across more than three decades is not any different from the 1980s' view that considers glyphosate to be safe and does not cause/pose carcinogenic risk to humans.

Data of the US Agricultural Health Study (AHS) were collected from over 57,000 pesticide applicators, reanalyzed and published in 2015 [37] to determine any possible relationship between glyphosate exposure and the risk of multiple myeloma. These results contradict the outcome of a previous analysis of AHS data that relied on a restricted data set and reached a different conclusion. This reanalysis of the full AHS data set is consistent with other epidemiological and laboratory research demonstrating that glyphosate does not create cancer risk to humans.

In 2015 a group of scientists from the German Federal Institute for Risk Assessment (BfR) published a review on seven studies that monitored glyphosate in human urine [38]. Because glyphosate is neither significantly metabolized nor significantly accumulated in humans after their exposure, it is rapidly excreted in their urine. By measuring urine levels it was possible to calculate internal exposure levels and actual risk. In a textbook example of risk assessment, the authors calculated the internal exposure levels and compared these levels to the 'acceptable daily intake (ADI)' or the 'acceptable operator exposure level (AOEL)' to measure the risk of glyphosate exposure to consumers and applicators, respectively. It was concluded that the levels of glyphosate found in human urine indicate that realistic/internal exposures are extremely low and far below the worst-case assumptions used by regulatory agencies, thereby posing no actual risk to human health.

\section{Conclusion}

No one can ever assess the 'actual' risk of any material to humans from epidemiological studies for we, human beings, are not laboratory animals standardized for strain, age, and physiological state; neither are we confined in laboratorycontrolled conditions. This does not undervalue the efforts of regulatory agencies/authorities in assessing the potential of any material to cause cancer and/or other chronic diseases to humans. However, any cancer classification system says nothing more than a potential hazard that will depend not only on exposure to the material itself, but also on the historical and current exposure to other materials that may or may not inherit a carcinogenic potential; some may only play a cancer-promoting role. It is understood that numbers do not lie but interpretation may, sometimes, outlie these numbers and the interpretation will always be subject to innocent, or otherwise, subjectivity. Therefore, the fact that different regulatory or science agencies classify pesticides -in our case glyphosate- differently is not surprising since agencies do not use the exact same bulk of information or the same standard(s) of high research quality. Besides, different interpretation is a matter of perceptual thinking skills which could be different from one assessor to the other and from one assessing group to the other. In the case of glyphosate, however, it seems that the perceptual bias holds with IARC rather than EPA, EU, BfR, PMRA, APMVA, etc. It is then our perception, as scientists, to go with the majority, until IARC is proven to be the exclusive right in this case. Therefore, continuing the use of glyphosate in Egypt seems justifiable and will not jeopardize the public health or the environment. However, not only is glyphosate used as five or more different salts but its commercial formulations contain surfactants, which vary in nature and concentration. As a result, human poisoning with this herbicide is not with the active ingredient alone but with complex and variable mixtures. Therefore, risk-reduction measures are critically required, regardless of how safe glyphosate or any other active ingredient is.

\section{A word to the public in Egypt and other developing countries}

The weight of evidence strongly suggests that glyphosate does not cause cancer-and if it does, a closer look at the situation in Egypt demonstrates a lack of significant dose/exposure to the public, especially as we use far less application rate than other countries wherein relationships between exposure and chronic human diseases have been documented. Therefore, the public can be confident that labeled uses of glyphosate products pose no calculated risk of cancer. Let's explain this notion much further. As toxicologists, we know the difference between hazard and risk. Risk always revolves around the dose (exposure). To state the obvious, the concept of dose doesn't even come into play if there is no exposure. In other words, if one is never exposed to a chemical, then one cannot possibly receive a dose. If there is a container of glyphosate in your kitchen, sitting unopened on a shelf, no one is being exposed to it. Likewise, aspirin in the bottle won't help your headache. Since Egypt does not grow genetically modified crops that are resistant to glyphosate, and due to the fact that glyphosate is not a selective herbicide, the Egyptian farmers would not risk losing their crops by unreasonably exceeding the application rate or increasing the frequency of glyphosate application. This herbicide is largely used against weeds in fruit fields/gardens by directing the application at basal weeds within and between fruit trees, ensuring that the foliage is not contacted. Besides, Egypt like other developing countries that have not yet adopted genetically engineered glyphosate-resistant crops, does not report weed populations with glyphosate resistance. Therefore, the Egyptian farmer has no reason to increase the rate and/or the frequency of glyphosate application. Using the above rationale, it is logically reasonable to imply/assume that the exposure of farmers, bystanders and consumers to glyphosate in developing countries, including Egypt, is expected to be fairly low.

If contact with a chemical occurs through inhalation, ingestion, or the skin, it is possible that the chemical may enter the body and result in a "dose." But simply receiving a dose isn't enough - that dose needs to be high enough and persistent enough for biochemical consequences to occur. 
Yehia A. Ibrahim, Journal of Toxicology and Health 2015,

Likewise, a couple of aspirin tablets may help your headache, but $1 / 100$ of an aspirin tablet won't. In seven studies from Europe and the USA [38], it appears that real-life exposure to glyphosate via food and the environment is orders of magnitudes lower than the ADI (Allowable or Acceptable Daily Intake). If we know that ADI itself is at least two orders of magnitudes less than the dose that causes no-observedadverse-effect (i.e., NOAEL or NOEL) in experimental animals, one can easily conclude that glyphosate is far less risky to human health than any worst case scenario of exposure. Furthermore, the Egyptian farmers use this herbicide rather conservatively due to the fact that it is not selective and can harm their host plants (crops). It is then expected that farmers applying glyphosate, as well as consumers, fall within many orders of magnitudes below the ADI value; thus indicating far less dose than the one that even elicits zero risk.

Furthermore, once a chemical gets absorbed into the body, it can be broken down (metabolized) by or excreted from the body. Metabolism can produce problems if the breakdown products are more toxic or reactive, and some chemicals can persist in the body - but what about glyphosate? Absorbed glyphosate is not readily or highly metabolized in humans, is not fat soluble, and does not accumulate in the body over time, but rather is excreted in the urine either unchanged or with its predominant metabolite, AMPA $[38,39]$.

Regardless of the system used for categorization of pesticides' carcinogenic potential, no legislative or regulatory recommendations are given, which are the responsibility of individual governments or through international agreement(s). To wrap it up here, it is to fairly say that Egypt's situation regarding glyphosate use does not warrant cancer risk to the public. Therefore, there is no need for needless panic, but self protection from any xenobiotic will always remain to be a responsible practice.

\section{Recommendations}

1. The database, on which the IARC evaluation is based, is not known because the background monograph that is usually produced by IARC following the evaluation meetings is not released yet. Therefore, a comprehensive and scientifically sound consideration of the data and arguments that led to the IARC conclusion is simply not possible at this moment. It is recommended, however, that glyphosate reassessment is required by APC once the IARC 112 monograph is fully published.

2. APC cannot undermine the IARC classification of glyphosate. Due to the position of the supranational pesticide regulatory authorities that clearly objects and contradicts the IARC classification, this herbicide may be considered unclassifiable as to its carcinogenic potential to humans for the time being. This recommendation is not because of any lack of study, for glyphosate has been subject to more than 40 years of toxicological research, but because of the extreme dispute in the classification among dif- ferent reputable organizations.

3. Since all the APC-Reference Regulatory Agencies/Authorities (EPA, EU, PMRA, APVMA) consider glyphosate as being safe and not carcinogenic to humans, and since we are not abide by IARC evaluation, we should follow our reference agencies/authorities for the time being or at least temporarily.

4. Until the dispute among the international community regarding glyphosate is settled or resolved, and due to the fact that glyphosate is the most commonly used herbicide in Egypt with no suitable substitutes, it can be continually used under RUP labeling conditions. Remember that glyphosate is the only commercial herbicide that belongs to group 9 in the classification of herbicides according to their mode(s) of action.

5. The situation in Egypt is so different from other countries in the world, especially those of north and south America, in that most of the recommended use of glyphosate is against weeds of the fruit trees and the chance of contaminating food and feed is very limited, especially if we consider that the application rate in Egypt is about twenty times lower than that in countries wherein association between exposure and chronic diseases have been documented. Recently, the author of this reviewbased report and Dr. Channa Jayasumana from Sri Lanka calculated human exposure to glyphosate in Egypt and Sri Lanka, and found that the Egyptian public is expected to be 77 times less exposed than the Sri Lankan public [40]. This may be due to the fact that Egypt does not grow genetically-engineered glyphosate-resistant crops and the populations of weeds are still susceptible to glyphosate herbicidal action. Therefore, the Egyptian farmers do not have to use higher or frequent doses of glyphosate, and cannot risk losing their crops by using higher or extra doses of this broad-spectrum, non-selective herbicide. It is recommended that APC, and other regulatory agencies, with similar situation(s), review all registered glyphosate-based formulations, and only deregulate those with the lowest percentages of active ingredient in their formulations.

6. As one of the seminal tenets of toxicology is that the dose makes the poison, and although the reality is that glyphosate, according to APC-Reference Regulatory Agencies, is not a human risk even at levels of exposure that are more than 100 times higher than the human exposure that may occur under conditions consistent with the product's labeling in Egypt, it is highly recommended that applicators and farm workers wear protecting clothes and equipment and the label should say so.

7. To protect workers entering treated sites, a restricted-entry interval of at least 12 hours is proposed for agricultural uses.

8. To protect bystanders, a statement indicating: "To apply only when the potential for drift to areas of human habita- 
tion or areas of human activity such as houses, cottages, schools and recreational areas is minimal."

9. Buffer zones to protect non-target terrestrial and aquatic habitats are required.

10. To reduce the potential for runoff of glyphosate to adjacent aquatic habitats, precautionary statements are required for sites with characteristics that may be conducive to runoff and when heavy rain is forecasted (Egypt sea coast: Alexandria, Ismailia, Marsa Matrouh, etc.). In addition, a vegetative strip between the treated area and the edge of a water body is recommended to reduce runoff of glyphosate to aquatic areas.

11. Glyphosate is very stable in the environment, especially in the soil where it binds to many soil types and clay materials, making it immobile; but under certain conditions it can be moved to groundwater when the soil particles are washed into streams or rivers. It may then affect soil microbes and fertility. Glyphosate has one major metabolite-namely, AMPA (Aminomethylphosphonic acid), which is considered to be more harmful on the environment than the parent compound itself. Therefore, it is recommended to have these two chemicals monitored in the Egyptian soil, surface water, groundwater and aquatic animals. Due to the fact that there are no available bio-monitoring data with regard to glyphosate and AMPA in Egyptian populations, it is also recommended that applicators, farmers and consumers are routinely monitored for the likely presence of these two compounds in their body and urine.

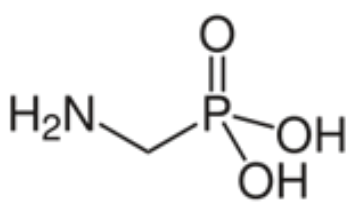

The Structure of AMPA (Aminomethylphosphonic acid)

12. Most pesticide formulations contain inert ingredients that function as surfactants which aid in the penetration of the herbicide to plant cells. In the case of many glyphosate-based formulations, the inert surfactant is polyethyloxylated tallowamine (POEA). On a weight basis, this surfactant is approximated to be three times as toxic as that of glyphosate [41]. According to PMRA [19], no human health risks of concern were identified, provided end-use products contain no more than $20 \%$ POEA by weight. To be even more conservative, it is recommended that POEA should be either not included in glyphosate-based formulations or not exceeding $15 \%$.<smiles>COCCN(P)C(C)(C)CCOC</smiles>

The Structure of POEA (Polyethoxylatedtallowamine)
13. Glyphosate and its breakdown products are long-lasting in surface waters, and highly toxic to aquatic life and amphibians that live in ponds, streams and sloughs. POEA, used in some glyphosate herbicide formulations, is highly toxic to amphibians and shellfish. It interferes with normal development; stunting growth and causing abnormalities in sex organs and tails in tadpoles [42]. Monsanto's product label notes that Roundup is toxic to aquatic organisms and instructs users to avoid direct applications to any body of water; observe buffer zones (50 feet for field sprayers, 100 feet for aerial sprayers); and to avoid contaminating water sources when disposing of waste or cleaning equipment [43]. We certainly adopt this recommendation and modify label instructions accordingly.

14. APC should encourage pesticide companies to apply for the registration of new herbicides that may replace glyphosate in the future.

15. There should be no future increase in the allowable quantity of glyphosate that will be imported to and/or used in Egypt at least during the next few year(s).

16. Because glyphosate and AMPA are commonly known to impair seed germination, glyphosate-based formulations should not be used on or nearby any crops grown for seed production.

17. As the frequency of root-colonizing Fusarium increased significantly after glyphosate application during growing seasons [44], it is recommended that some rationallyselected fungicides be used with or following glyphosate treatments.

18. Currently glyphosate dominates weed control in Egypt, comprising about 70\% of all herbicides used during 2014 (APC database). Overreliance on glyphosate without diversity in weed control practices will be detrimental to the herbicide's sustainability in the long run due to the selective pressure favoring the evolution of glyphosateresistant weeds. The spread of resistant genomes and the shift in the weed species will negatively affect crop productivity. Therefore, it is highly recommended to begin weed control practices that use other herbicides with different mode(s) of action either in rotation or in a tank-mix with glyphosate. It is recommended here that glyphosate is used at lower doses when mixed with other herbicides than when applied alone. This will decrease human and environmental exposure to glyphosate on one hand, and decrease the selective pressure of glyphosate on weed populations on the other hand.

19. Complementary with the above recommendation, it is important to note that knowing the herbicide classes according to their mode(s) of action is the key to planning a management strategy to reduce the potential for the likely development of resistant weeds. Therefore, it is also recommended to include the class or classes of each herbicide used in Egypt in its label. 
Yehia A. Ibrahim, Journal of Toxicology and Health 2015,

20. Since Egypt imports grains from foreign countries, wherein glyphosate-resistant GM crops are widely grown, it would be necessary for the Egyptian government to restrict imported grains that contain high levels of glyphosate and/or its AMPA metabolite.

\section{List of abbreviations}

APC: Egypt Agricultural Pesticide Committee

IARC: International Agency for Research on Cancer

BfR: German Federal Institute for Risk Assessment

EFSA: European Food Safety Authority

EPA: US Environmental Protection Agency

PMRA: Canada Pest Management Regulatory Agency

APVMA: Australian Pesticides and Veterinary Medicines Authority WHO: World Health Organization

FAO: Food and Agriculture Organization

EPSPS: 5-enolpyruvylshikimate-3-phosphate synthase

Competing interests

The author declares that he has no competing interests.

\section{Acknowledgement}

The author wishes to acknowledge the precious time granted by Dr. Nancy Swanson, Dr. Channa Jayasumana and Dr. Lars Niemann to discuss some of the author's ideas. The great cooperation of the supranational pesticide regulatory agencies/authorities, especially EPA, PMRA, APVMA, BfR, EFSA, EC, and EU in responding to the author's questions and concerns proves that they have an international dimension to their national missions. The author wishes to express his sincere thanks to Dr. Mona K. Ibrahim for patiently and skillfully editing this manuscript. Last but far from least, the author is indebted to the anonymous reviewers and editors of the Journal of Toxicology and Health whose comments have added depth, clarity and authenticity to this manuscript.

Publication history

Editor: Cengiz Gokbulut, Balikesir University, Turkey.

Received: 29-Jul-2015 Final Revised: 10-Sep-2015

Accepted: 18-Sep-2015 Published: 26-Sep-2015

\section{References}

1. Franz JE, Mao M.K and Sikorski J.A. Glyphosate: A Unique and Global Herbicide, ACS Monograph No. 189. American Chemical Society, Washington, DC, 1997; 653.

2. Williams GM, Kroes R and Munro IC. Safety evaluation and risk assessment of the herbicide Roundup and its active ingredient, glyphosate, for humans. Regul Toxicol Pharmacol. 2000; 31:117-65. | Article | PubMed

3. Steinrucken $\mathrm{HC}$ and Amrhein $\mathrm{N}$. The herbicide glyphosate is a potent inhibitor of 5-enolpyruvyl-shikimic acid-3-phosphate synthase. Biochem Biophys Res Commun. 1980; 94:1207-12. | Article I PubMed

4. Herrmann KM and Weaver LM. The Shikimate Pathway. Annu Rev Plant Physiol Plant Mol Biol. 1999; 50:473-503. | Article | PubMed

5. U.S. Environmental Protection Agency. Pesticide fact sheet: Glyphosate. No. 173. Washington, D.C.: Office of Pesticide Programs. 1986. | Pdf

6. U.S. Environmental Protection Agency. EPA: Glyphosate. EPA738-F-93-011. U.S. Environmental Protection Agency, Washington, DC. Df. 1993. | Pdf

7. IARC/WHO. 2015. I Pdf

8. Guyton KZ, Loomis D, Grosse Y, El Ghissassi F, Benbrahim-Tallaa L, Guha N, Scoccianti C, Mattock H and Straif K. Carcinogenicity of tetrachlorvinphos, parathion, malathion, diazinon, and glyphosate. Lancet Oncol. 2015; 16:490-1. | Article | PubMed
9. Duke SO and Powles SB. Glyphosate: a once-in-a-century herbicide. Pest Manag Sci. 2008; 64:319-25. | Article | PubMed

10. Duke S.O, Baerson S.R and Rjmando A.M. Herbicides: glyphosate, in Encyclopedia of Agrochemicals, ed. by Plimmer, J.R., Gammon, D.W. and Ragsdale, N.N. John Wiley \& Sons, Inc., New York, NY. 2003. | Book

11. Cerdeira AL and Duke SO. The current status and environmental impacts of glyphosate-resistant crops: a review. J Environ Qual. 2006; 35:163358. | Article | PubMed

12. WHO/FAO. Pesticides residues in food-1986. Report of the Joint Meeting of the FAO Panel of Experts on Pesticide Residues in Food and the Environment and the WHO Core Assessment Group on Pesticide Residues (JMPR). 1986. | Website

13. WHO. Glyphosate. Environmental Health Criteria No. 159. World Health Organization, Geneva. I Website

14. WHO/FAO. Pesticides residues in food-2004. Report of the Joint Meeting of the FAO Panel of Experts on Pesticide Residues in Food and the Environment and the WHO Core Assessment Group on Pesticide Residues (JMPR). 2004. I Pdf

15. FAO. FAO Specifications and Evaluations for Agricultural Pesticides. Glyphosate N-(phosphonomethyl) glycine. 2014. I Website

16. European Commission Health \& Consumer Protection DirectorateGeneral. Directorate E - Food Safety: plant health, animal health and welfare, international questions E1 - Plant health Glyphosate 6511/ VI/99-final 21 January 2002. Review report for the active substance glyphosate Finalised in the Standing Committee on Plant Health at its meeting on 29 June 2001 in view of the inclusion of glyphosate in Annex I of Directive 91/414/EEC, 2002. I Pdf

17. U.S. Environmental Protection Agency. Personal Communication. 2015

18. Doliner L.H. Pre-Harvest use of glyphosate herbicide [Preharvest application of glyphosate (Roundup) herbicide]. Discussion Document D91-01. Pesticide Information Division, Plant Industry Directorate, Agriculture Canada. 1991; 98.

19. PMRA. 2015. | Website

20. Argentine Interdisciplinary Scientific Council. 2009. I Pdf

21. Australian Government, Australian Pesticides and Veterinary Medicines Authority. 2013. I Pdf

22. Australian Government, Australian Pesticides and Veterinary Medicines Authority. 2015. | Website

23. BfR statement. 2015. I Pdf

24. Glyphosate: no more poisonous than previously assumed, although a critical view should be taken of certain co-formulants. 2015. | Website

25. The BfR has finalised its draft report for the re-evaluation of glyphosate. 2015. | Website

26. Bfr-contribution-to-the-eu-approval-process-of-glyphosate-is-finalised. 2015. I Pdf

27. Swanson N.L, Leu A, Abrahamson J and Wallet B. Genetically engineered crops, glyphosate and the deterioration of health in the United States of America. Journal of Organic Systems. 2014; 9:6-37. I Pdf

28. Jayasumana C, Gunatilake S.and Senanayake P. Glyphosate, Hard Water and Nephrotoxic Metals: Are They the Culprits Behind the Epidemic of Chronic Kidney Disease of Unknown Etiology in Sri Lanka? International Journal of Environmental Research and Public Health. 2014; 11:21252147. I Article

29. Seralini GE, Clair E, Mesnage R, Gress S, Defarge N, Malatesta M, Hennequin D and de Vendomois JS. Long term toxicity of a Roundup herbicide and a Roundup-tolerant genetically modified maize. Food Chem Toxicol. 2012; 50:4221-31. | Article | PubMed

30. Swanson NL. Personal Communication. 2015.

31. Jayasumana C. Personal Communication. 2015.

32. Elsevier Announces Article Retraction from Journal Food and Chemical Toxicology. 2013. | Website

33. Mink PJ, Mandel JS, Sceurman BK and Lundin JI. Epidemiologic studies of glyphosate and cancer: A review. Regulatory Toxicology and Pharmacology. 2012; 63:440-452. | Article 
Yehia A. Ibrahim, Journal of Toxicology and Health 2015,

34. Kier LD and Kirkland DJ. Review of genotoxicity studies of glyphosate and glyphosate-based formulations. Crit Rev Toxicol. 2013; 43:283-315. | Article | PubMed

35. Kier LD. Review of genotoxicity biomonitoring studies of glyphosatebased formulations. Crit Rev Toxicol. 2015; 45:209-18. | Article | PubMed

36. Greim H, Saltmiras D, Mostert V and Strupp C. Evaluation of carcinogenic potential of the herbicide glyphosate, drawing on tumor incidence data from fourteen chronic/carcinogenicity rodent studies. Crit Rev Toxicol. 2015; 45:185-208. | Article | PubMed

37. Sorahan T. Multiple myeloma and glypho

38. Sate use: a re-analysis of US Agricultural Health Study (AHS) data. Int J Environ Res Public Health. 2015; 12:1548-59. | Article I PubMed Abstract I PubMed Full Text

39. Niemann L, Sieke C, Pfeil R and Solecki R. A critical review of glyphosate findings in human urine samples and comparison with the exposure of operators and consumers. Journal für Verbraucherschutz und Lebensmittelsicherheit (J. Consum. Protect. Food Safety). 2015; 10:3-12. | Article

40. Greenberg MI. What-can-we-say-about-exposure-glyphosate. 2015. | Website

41. Ibrahim Y.A and Jayasumana C. Unpublished data. 2015

42. Sawada Y, Nagai Y, Ueyama M and Yamamoto I. Probable toxicity of surface-active agent in commercial herbicide containing glyphosate. Lancet. 1988; 1:299. | Article | PubMed

43. Howe $C$, Berrill M and Pauli BD. The Acute and Chronic Toxicity of Glyphosate-Based Pesticides in Northern Leopard Frogs. 2015. | Article

44. Product label. Roundup Weather MAX With Transorb 2 Technology Liquid Herbicide. 2015. I Pdf

45. Kremer RJ and Means NE. Glyphosate and glyphosate-resistant crop interactions with rhizosphere microorganisms. European Journal of Agronomy. 2009; 31:153-161. I Article

\section{Citation:}

Ibrahim YA. A regulatory perspective on the potential carcinogenicity of glyphosate. J Toxicol Health. 2015; 2:1. http://dx.doi.org/10.7243/2056-3779-2-1 